\title{
PENERAPAN STRATEGI PEMBELAJARAN CIRCUIT LEARNING TERHADAP HASIL BELAJAR MATEMATIKA SISWA KELAS VI SD NEGERI BAWAKARAENG 1 MAKASSAR
}

\author{
Andi Ardhila Wahyudi, Hamdana Hadaming \\ Pendidikan Guru Sekolah Dasar, Fakultas Keguruan dan Ilmu Pendidikan \\ Universitas Muhammadiyah Makassar \\ Hamdana9901@gmail.com
}

\begin{abstract}
ABSTRAK
Jenis penelitian ini adalah penelitian pre-eksperimen yang melibatkan satu kelas sebagai kelas eksperimen dengan tujuan untuk mengetahui hasil belajar matematika, siswa kelas VI SD Negeri Bawakaraeng 1 Makasar. Desain penelitian yang digunakan adalah the one group pretestposttest, yaitu suatu penelitian yang dilaksanakan tanpa adanya kelompok perbandingan tetapi dilakukan tes awal. Subjek Penelitian adalah siswa kelas VI SD Negeri Bawakaraeng 1 Makasar yang berjumlah 34 siswa yang terdiri dari 18 siswa perempuan dan 16 siswa laki-laki pada tahun pelajaran 2017/2018. Teknik pengumpulan data yang digunakan adalah tes hasil belajar untuk mengukur hasil belajar setelah mengikuti pembelajaran dengan menggunakan strategi circuit learning. Data yang telah diperoleh dianalisis dengan menggunakan analisis deskriptif. Hasil analisis menunjukkan bahwa: nilai rata-rata tes awal (Pretest) hasil belajar matematika siswa adalah 56,13 dari 34 siswa dimana hanya 6 atau 17,65\% yang memenuhi kriteria minimal (KKM) atau berada pada kategori Sangat Rendah. Sedangkan nilai rata-rata tes akhir (posttest) hasil belajar matematika siswa adalah 79,17 dari 34 siswa dimana 29 atau 85,29\% yang memenuhi Kriteria ketuntasan minimal (KKM) atau berada pada kategori sedang, Besar peningkatan hasil belajar matematika siswa kelas Kelas VI SD Negeri Bawakaraeng 1 Makassar dapat diketahui dari uji-gain melalui skor rata-rata pretest dan posttest siswa. Nilai Gain yang diperoleh sebesar 0,51 dan berada pada kategori sedang dengan melihat tabel kriteria N-Gain. Berdasarkan hal tersebut dapat diketahui bahwa peningkatan hasil belajar matematika siswa setelah di ajar dengan strategi Circuit Learning berada pada kategori sedang.
\end{abstract}

Kata kunci : Hasil Belajar, Circuit Learning 


\begin{abstract}
This type of research is a pre-experimental study involving one class as an experimental class with the aim of knowing the results of learning mathematics, class VI SD Negeri Bawakaraeng 1 Makassar. The research design used was the one group pretest-posttest, which was a study carried out in the absence of a comparison group but carried out initial tests. The research subjects were class VI students of SD Negeri Bawakaraeng 1 Makassar, which numbered 34 students consisting of 18 female students and 16 male students in the 2017/2018 school year. The data collection technique used is a test of learning outcomes to measure learning outcomes after participating in learning using circuit learning strategies. The data that has been obtained is analyzed using descriptive analysis. The results of the analysis show that: the average pretest score of students' mathematics learning outcomes is 56.13 out of 34 students where only 6 or $17.65 \%$ meet the minimum criteria (KKM) or are in the Very Low category. While the average score of the final test (posttest) of students' mathematics learning outcomes is 79.17 out of 34 students where 29 or $85.29 \%$ meet the minimum completeness criteria (KKM) or are in the moderate category. VI Makassar Bawakaraeng 1 Elementary School can be known from the gain test through the students' average pretest and posttest scores. Gain value obtained is 0.51 and is in the medium category by looking at the N-Gain criteria table. Based on this, it can be seen that the increase in mathematics learning outcomes of students after being taught with the Circuit Learning strategy is in the medium category.
\end{abstract}

Keywords: Learning achievement, Circuit Learning 


\section{PENDAHULUAN}

Seiring dengan perkembangan zaman ilmu pengetahuan pun semakin maju, oleh karena itu setiap ilmu pengetahuan perlu dikembangkan karena sarana yang digunakan semakin canggih dan modern sehingga sumber daya manusia harus mampu mengikuti perkembangan tersebut, dan salah satu bidang ilmu pengetahuan itu adalah Matematika. Mempelajari matematika merupakan sarana berpikir ilmiah dan berpikir logis serta mempunyai peranan penting dalam upaya peningkatan kualitas sumber daya manusia. Selain itu, penguasaan materi matematika sangat membantu dan menjadi sarana yang penting dalam penguasaan Ilmu Pengetahuan dan Teknologi (IPTEK).

$$
\text { Pembelajaran matematika }
$$

sangatlah penting, karena matematika merupakan sarana untuk memecahkan masalah kehidupan sehari-hari. Pendidikan matematika di tanah air saat ini sedang mengalami perubahan paradigma. Terdapat kesadaran yang kuat, terutama di kalangan pengambil kebijakan, untuk memperbaharui pendidikan matematika. Tujuannya adalah agar pembelajaran matematika lebih bermakna bagi siswa dan dapat memberikan bekal kompetensi yang memadai baik untuk studi lanjut maupun untuk memasuki dunia kerja (Sutarto Hadi, 2005). Tidak dipungkiri lagi bahwa matematika banyak memiliki kegunaan dan kegunaan matematika tidak hanya tertuju pada peningkatan kemampuan perhitungan campuran kuantitatif saja tetapi juga untuk penataan cara berfikir, khususnya dalam pembentukan kemampuan analisis, membuat sintesis dan evaluasi hingga mampu memecahkan masalah.

$$
\text { Masalah utama dalam }
$$

pembelajaran matematika adalah masih rendahnya daya serap peserta didik. Permasalahan ini tampak dari rerata hasil belajar peserta didik yang masih sangat memprihatinkan. Di sekolah, banyak siswa tampaknya menjadi tidak tertarik dengan matematika ini dikarenakan belum tepatnya cara penyampaian materi kepada siswa sehingga menyebabkan siswa kesulitan dalam menerima pelajaran. Sebagian besar guru masih mengimplementasikan pembelajaran matematika tradisional yaitu pembelajaran matematika dengan mengandalkan metode tunggal ekspositori dengan siklus; menjelaskan, memberi contoh, mengajukan pertanyaan, dan memberi tugas secara klasikal. Metode seperti ini 
mengakibatkan proses pembelajaran berpusat pada guru dan proses pembelajaran hanya dikuasai oleh guru. Sehingga minat siswa dalam pembelajaran matematika kurang yang mengakibatkan pemahaman dan penguasaan materi cenderung rendah. Kondisi tersebut akhirnya berdampak pada hasil belajar siswa yang kurang maksimal.

Berdasarkan hasil wawancara dengan salah satu guru kelas VI DI SD Negeri Bawakaraeng 1 bahwa sekitar 65\% nilai hasil belajar matematika siswa masih berada di bawah KKM yaitu 75. Untuk mengatasi masalah tersebut , maka peneliti menerapkan salah satu strategi pembelajaran yaitu dengan menerapkan strategi pembelajaran Circuit Learning .

Circuit learning adalah model pembelajaran yang merupakan turunan dari pendekatan berpikir dan berbasis masalah. Dalam pendekatan ini, siswa diharapkan mampu memiliki "kompetensi meneliti, mengemukakan pendapat, menerapkan pengetahuan sebelumnya, memunculkan ide-ide baru, membuat keputusan-keputusan, mengorganisasi ide-ide, membuat hubungan-hubungan, menghubungkan wilayah-wilayah interaksi dan mengapresiasi kebudayaan"(Huda, 2013, hlm. 270).

Model pembelajaran Circuit Learning dijadikan peneliti dan kolabolator karena model pembelajaran ini adalah salah satu model pendekatan berpikir dan berbasis masalah yang mampu mengajak siswa untuk memaksimalkan pemberdayaan pikiran dan perasaan dengan pola penambahan (adding) dan pengulangan (repetition) yang dimulai dari tanya jawab tentang topik yang dipelajari, penyajian peta konsep, penjelasan mengenai peta konsep, pembagian ke dalam beberapa kelompok, pengisian lembar kerja siswa disertai dengan peta konsep, penjelasan tentang tata cara pengisian, pelaksanaan presentasi kelompok, dan pemberian reward atau pujian (Huda, 2013:311). Circuit learning dapat menambah kreativitas siswa dan mengaktifkan siswa karena membuat pengetahuan siswa yang didapat dalam pembelajaran dialami sendiri oleh siswa sehingga menjadi bermakna dan sulit dilupakan. De Porter (2012: 230) mengemukakan tujuan model pembelajaran circuit learning yaitu, mengajarkan keadaan prima dalam belajar sehingga mencegah rasa takut, jenuh, pikiran negatif, bosan dan tidak percaya diri dalam belajar. 


\section{METODE PENELITIAN}

Jenis penelitian ini adalah penelitian pre-eksperimen yang melibatkan satu kelas sebagai kelas eksperimen dengan tujuan untuk mengetahui hasil belajar matematika siswa kelas VI SD Negeri Bawakaraeng 1 Makassar. Desain penelitian yang digunakan adalah the one group pretest-posttest, yaitu suatu penelitian yang dilaksanakan tanpa adanya kelompok perbandingan tetapi dilakukan tes awal. Subjek Penelitian adalah siswa kelas VI SD Negeri Bawakaraeng 1 Makassar yang berjumlah 34 siswa yang terdiri dari 18 siswa perempuan dan 16 siswa laki-laki. Teknik pengumpulan data yang digunakan adalah tes hasil belajar untuk mengukur hasil belajar setelah mengikuti pembelajaran dengan strategi Circuit Learning. Sebelum diujikan kepada sampel maka soal tes diuji coba dahulu di SD Negeri Sangir untuk mengetahui kriteria validitas, reliabilitas, taraf kesukaran, dan daya pembeda soal. Hal ini dikarenakan agar butir soal yang digunakan dalam penelitian dapat mengukur kemampuan siswa sebenarnya.

\section{HASIL PENELITIAN DAN PEMBAHASAN}

Berdasarkan penelitian yang dilakukan pada siswa kelas VI SD Negeri Bawakaraeng 1 Makassar nilai rata-rata tes awal (Pretest) hasil belajar matematika siswa adalah 56,13 dari 34 siswa hanya 6 atau 17,65\% yang memenuhi kriteria minimal (KKM) atau berada pada kategori Sangat Rendah. Sedangkan nilai rata-rata tes akhir (posttest) hasil belajar matematika siswa adalah 79,17 dari 34 siswa 29 atau $85,29 \%$ yang memenuhi Kriteria ketuntasan minimal (KKM) atau berada pada kategori sedang, Berikut ini dikemukakan hasil analisis pencapaian hasil belajar matematika siswa kelas VI SD Negeri Bawakaraeng 1 Makassar Tahun Ajaran 2017/2018 yang diajar dengan penerapan strategi pembelajaran Circuit Learning. 
Tabel. 1 Hasil Belajar Matematika Secara Umum Siswa Kelas VI SD Negeri Bawakaraeng 1 Makassar

\begin{tabular}{|c|c|c|}
\hline Skor & Pretest & Posttest \\
\hline Ukuran Sampel & 34 & 34 \\
\hline Skor ideal & 12 & 12 \\
\hline Skor tertinggi & 9 & 12 \\
\hline Skor terendah & 3 & 7 \\
\hline Rentang Skor & 6 & 5 \\
\hline Skor rata-rata & 6,74 & 9,5 \\
\hline Nilai rata-rata & 56,13 & 79,17 \\
\hline
\end{tabular}

Berdasarkan tabel 1 skor tertinggi diperoleh siswa adalah 12 menunjukkan bahwa hasil belajar dan skor terendahnya adalah 7 , dan matematika sebelum penerapan strategi standar nilai rata-rata diperoleh 79,17. pembelajaran Circuit Learning (pretest) Berikut adalah hasil belajar matematika diperoleh skor tertinggi siswa adalah 9 sebelum dan sesudah peneraapan dan skor terendahnya adalah 3 , dan srategi pembelajaran Circuit Learning standar nilai rata-rata diperoleh 56,13. siswa kelas VI SD Negeri Bawakaraeng 1 Sedangkan hasil belajar matematika Makassar. Dapat dilihat pada tabel setelah penerapan strategi dibawah ini.

pembelajaran Circuit Learning (posttest)

Tabel 2 Frekuensi dan Presentase Skor Hasil Belajar Matematika Siswa Kelas VI SD Negeri Bawakaraeng 1 Makassar Sebelum (pretest) dan sesudah (posttest) peneraapan srategi pembelajaran Circuit Learning

\begin{tabular}{|c|c|c|c|c|c|}
\hline $\begin{array}{c}\text { Tingkat } \\
\text { Penguasaan }\end{array}$ & Kategori & $\begin{array}{c}\text { Frekuensi } \\
\text { pretest }\end{array}$ & $\begin{array}{c}\text { Presentase } \\
(\%)\end{array}$ & $\begin{array}{c}\text { Frekuensi } \\
\text { Postest }\end{array}$ & $\begin{array}{c}\text { Persentase } \\
(\%)\end{array}$ \\
\hline$<60$ & $\begin{array}{c}\text { Sangat } \\
\text { Rendah }\end{array}$ & 19 & 55,9 & 1 & 2,9 \\
\hline $60-69$ & Rendah & 9 & 26,5 & 4 & 11,8 \\
\hline $70-79$ & Sedang & 6 & 17,6 & 12 & 35,3 \\
\hline $80-89$ & Tinggi & 0 & 0 & 13 & 38,2 \\
\hline
\end{tabular}




\begin{tabular}{|c|c|c|c|c|c|}
\hline $90-100$ & $\begin{array}{r}\text { Sangat } \\
\text { Tinggi }\end{array}$ & 0 & 0 & 4 & 11,8 \\
\hline \multicolumn{2}{|c|}{ Jumlah } & 34 & 100 & 34 & 100 \\
\hline
\end{tabular}

Berdasarkan Tabel.2 diatas dapat dilihat bahwa persentase nilai siswa kelas VI SD Negeri Bawakaraeng pada kategori sangat rendah mengalami penurunan, dapat dilihat bahwa saat pretest siswa kelas VI yang berada pada kategori sangat rendah berjumlah 19 siswa, dan setelah postest terjadi penurunan yang mana siswa kelas VI yang berada pada kategori sangat rendah berkurang menjadi 1 siswa saja. Sebaliknya, pada kategori tinggi dan sangat tinggi saat pretest tidak ada satupun siswa yang berada pada kategori tersebut, namun setelah penerapan strategi pembelajaran Circuit Learning terjadi peningkatan yang signifikan yaitu terdapat 13 siswa yang berada pada kategori tinggi dan 4 siswa yang berada pada kategori sangat tinggi. Sehingga dapat disimpulkan bahwa terjadi peningkatan hasil belajar siswa SD Negeri Bawakaraeng 1 Makassar setelah penerapan strategi pembelajaran Circuit Learning.

Kemudian untuk ketuntasan hasil belajar matematika sebelum penerapan strategi pembelajaran Circuit Learning (pretest) dan sesudah penerapan strategi pembelajaran Circuit Learning (postest) siswa kelas kelas VI SD Negeri Bawakaraeng Makassar ditunjukkan pada tabel berikut.

Tabel 3 Frekuensi dan Presentase Ketuntasan Skor Hasil Belajar Matematika Siswa Kelas VI SD Negeri Bawakaraeng Makassar Sebelum dan sesudah penerapan strategi pembelajaran Circuit Learning

\begin{tabular}{|c|c|c|c|c|c|}
\hline Nilai & Kategori & $\begin{array}{c}\text { Frekuensi } \\
\text { pretest }\end{array}$ & Presentase(\%) & $\begin{array}{c}\text { Frekuensi } \\
\text { postest }\end{array}$ & $\begin{array}{c}\text { Presentase } \\
(\%)\end{array}$ \\
\hline$<75$ & Tidak Tuntas & 28 & 82,35 & 5 & 14,71 \\
\hline$\geq 75$ & Tuntas & 6 & 17,65 & 29 & 85,29 \\
\hline \multicolumn{2}{|c|}{ Jumlah } & 34 & 34 & 100 & 100 \\
\hline
\end{tabular}


Berdasarkan Tabel 3 di atas bahwa saat pretest terdapat 28 siswa atau $82,35 \%$ yang tidak tuntas, namun setelah postest terjadi penurunan siswa yang tidak tuntas sisa 5 siswa atau $14,71 \%$. Sedangkan terjadi peningkatan ketuntasan hasil belajar yang mana saat pretest terdapat 6 siswa atau 17,65\% yang tuntas dan setelah postest terjadi peningkatan siswa yang tuntas sebanyak 29 siswa atau 85,29\% yang tuntas.

Besar peningkatan hasil belajar matematika siswa kelas VI SD Negeri Bawakaraeng 1 Makassar yang dihitung dengan menggunakan rentang Gain ditunjukkan pada tabel berikut.

Tabel 4 Frekuensi dan Presentase Peningkatan Hasil Belajar Matematika Siswa Kelas VI SD Negeri Bawakaraeng 1 Makassar Berdasarkan Rentang Gain

\begin{tabular}{|c|c|c|c|c|}
\hline No & Rentang & Kategori & Frekuensi & Persentase(\%) \\
\hline 1 & $\mathrm{~g}>0,7$ & Tinggi & 4 & 11,8 \\
\hline 2 & $0,3 \leq \mathrm{g} \leq 0,7$ & Sedang & 19 & 55,9 \\
\hline 3 & $\mathrm{~g}<0,3$ & Rendah & 11 & 11,8 \\
\hline \multicolumn{3}{|c|}{ Jumlah } & 34 & 100 \\
\hline
\end{tabular}

Besar peningkatan hasil belajar matematika siswa kelas Kelas VI SD Negeri Bawakaraeng 1 Makassar dapat diketahui dari uji-gain melalui skor ratarata pretest dan posttest siswa. Nilai Gain yang diperoleh sebesar 0,51 dan berada pada kategori sedang dengan melihat tabel kriteria N-Gain. Berdasarkan hal tersebut dapat diketahui bahwa peningkatan hasil belajar matematika siswa setelah di ajar dengan strategi Circuit Learning berada pada kategori sedang.

\section{KESIMPULAN}

Berdasarkan hasil penelitian yang telah dilaksanakan di SD Negeri Bawakaraeng 1 Makassar tentang penerapan strategi pembelajaran circuit learning terhadap hasil belajar matematika siswa kelas VI dapat disimpulkan nilai rata-rata tes awal (Pretest) hasil belajar matematika siswa adalah 56,13 dari 34 siswa hanya 6 atau $17,65 \%$ yang memenuhi kriteria minimal (KKM) atau berada pada kategori Sangat Rendah. Sedangkan nilai 
rata-rata tes akhir (posttest) hasil belajar matematika siswa adalah 79,7 dari 34 siswa 29 atau 85,29\% yang memenuhi kriteria ketuntasan minimal (KKM) atau berada pada kategori sedang. Sehingga dapat disimpulkan bahwa terjadi peningkatan hasil belajar matematika siswa kelas VI SD Negeri Bawakaraeng 1 setelah penerapan pembelajaran strategi Circuit Learning. Berdasarkan Uji Gain Besar peningkatan hasil belajar matematika siswa kelas VI SD Negeri Bawakaraeng 1 Makassar yang dihitung melalui skor rata-rata pretest dan posttest siswa diperoleh sebesar 0,51 dan berada pada kategori sedang.

\section{UCAPAN TERIMA KASIH}

Rasa hormat dan Ucapan terima kasih disampaikan kepada ayahanda dan ibundaku yang selalu memberikan nasehat dan motivasi, serta kepala sekolah SD Negeri Bawakaraeng 1 Makassar yang telah memberi izin untuk melakukan penelitian. Dan terima kasih kepada semua pihak yang telah membantu selama penelitian ini dilakukan.

\section{DAFTAR PUSTAKA}

DePorter, B. 2012. Quantum Teaching Mempraktikkan Quantum Learning di Ruang Kelas. Bandung: PT Mizan Pustaka

Hadi, S. (2005). Pendidikan Matematika Realistik dan Implementasinya. Banjarmasin :Tulip Banjarmasin

Huda, Miftahul. 2013. Model-Model Pengajaran dan Pembelajaran. Yogyakarta: Pustaka Belajar.

Huda, M. (2013). Cooperative Learning Metode, Teknik, Struktur dan Model Terapan. Yogyakarta: Pustaka Pelajar. 